\title{
Erratum to: Effect of alcohols on the heat of micellization of Pluronic F88 aqueous solutions
}

\author{
Ya-Hui Hsu ${ }^{1}$ - Hung-Wei Tsui ${ }^{1,2}$ • Chin-Fen Lee ${ }^{1} \cdot$ Shin-Hong Chen ${ }^{1} \cdot$ Li-Jen Chen $^{1}$
}

Published online: 14 September 2015

(C) Springer-Verlag Berlin Heidelberg 2015

\section{Erratum to: Colloid Polym Sci}

DOI 10.1007/s00396-015-3662-0

The original version of this article, unfortunately contained errors.

The image of Fig. 4 is incorrect. The correct image is given below.

The online version of the original article can be found at http://dx.doi.org/ $10.1007 / \mathrm{s} 00396-015-3662-0$.

Li-Jen Chen

ljchen@ntu.edu.tw

1 Department of Chemical Engineering, National Taiwan University, Taipei 10617, Taiwan

2 Department of Chemical Engineering and Biotechnology, National Taipei University of Technology, Taipei 10608, Taiwan
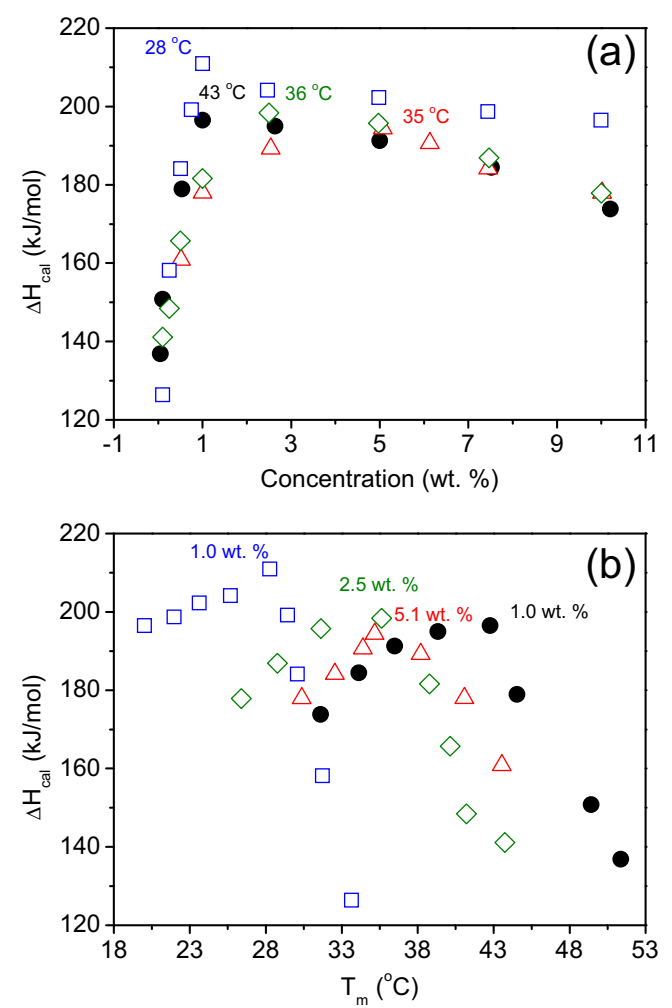

Fig. 4 Plots of $\mathbf{a} \Delta \mathrm{H}_{\mathrm{cal}}(\mathrm{kJ} / \mathrm{mol})$ vs. the Pluronic F88 concentration and $\mathbf{b}$ $\Delta \mathrm{H}_{\text {cal }}(\mathrm{kJ} / \mathrm{mol}) \mathrm{vs} . \mathrm{T}_{\mathrm{m}}$ for the Pluronic F88 solution in the presence of $0 \mathrm{wt}$ $\%(\bullet), 0.5$ wt $\%(\triangle), 2.5$ wt $\%(\diamond)$, and 5 wt $\%(\square) 1$-butanol 